\title{
Study of Factors Affecting Students' Performance in three Sci- ence Classes: General Biology, Botany, and Microbiology at Fayetteville State University
}

\author{
Stella K. Kantartzi ${ }^{1}$, Sherrice Allen ${ }^{2}$, Khalid Lodhi ${ }^{2}$, Robert L. Grier IV², and My Abdelmajid \\ Kassem $^{1 *}$ \\ 'Department of Plant, Soil, and Agricultural Systems, Southern Illinois University, Carbondale, IL, USA. ${ }^{2}$ De- \\ partment of Biological Sciences, Fayetteville State University, Fayetteville, NC 28301-4298, USA.
}

Received: June 28, 2010 / Accepted: October 18, 2010

\begin{abstract}
Several studies have reported the effects of class time on overall students' performances, but there are just few on the influence of factors as absences, gender, class section, class difficulty or semester. The objectives of this study were to analyze the effects of the above mentioned factors (absences, class time, gender, class difficulty and semester) on college students' performance in three science classes: Principles of Biology (BIOL 150), General Botany (BOTN 210), and Microbiology \& Immunology (BIOL 330) over a period of 3 years. Analysis of variance (ANOVA) for absences showed significant differences for the number of those between the different semesters (fall, spring, and summer) and that students tend to miss more classes ( $P>0.05)$ during fall and spring than summer semesters. Gender $(P>0.3515)$ and class section $(P>0.0608)$ do not seem to significantly affect the average grades in general biology and microbiology. Regarding gender, significant differences were observed in BOTN 210 between females and males average grades. Females tend to do better than males at least in this class. There was a moderate but strongly significant negative correlation (-0.59, $\mathrm{P}>0.0001^{* * *}$ ) between the average grades and the number of absences in almost all classes. ANOVA also showed significant differences for the average grades between the different class times at $P>0.0020 *$. The Tukey-Kramer test revealed that students perform better in morning classes compared to afternoon classes. The class time plays a significant role in the number of absences as well. Analysis showed that the most "convenient" time for students is late morning or after
\end{abstract}

noon given that they tend to result in fewer absences. In addition, students tend to receive better grades in BOTN 210 that they do in BIOL 330 and BIOL 150 (Means 77.33, 69.42, and 67.82 , respectively) which can be justified by the fact that the latter two are more intense than the first. Overall, absences are the only factor among those studied (absences, gender, class section, class difficulty and semester) that seem to affect student's grades negatively in all three classes (BIOL 150, BOTN 210 and BIOL 330). Typically, factors such as gender, and class section do not have any effect on students' performance. Results for class time show that students may perform better in morning or evening classes. In other cases time does not play any significant role to efficiency.

\section{Introduction}

Few studies at the beginning of last century reported the effects of time of day on memory (Gates, 1916; Laird, 1925) but such studies have increased in the last decades. Currently, there is ample evidence that memory is influenced by time of day. Several research findings reported that time of the day, circadian type, and class difficulty exert tremendous influences on students' ability to comprehend subject matter and their overall performance in class.

Natale and Lorenzetti (1997) investigated how time of the day affects narrative comprehension in evening and morning using human subjects. They found that immediate memory per- 
formance was better in the afternoon vs. morning for afternoon types than for morning types and vice versa.

In addition, the influence of the day on the performance variations of morning and evening types was studied using four different tasks: logic reasoning, visual search, mathematical reasoning and spatial reasoning. It was reported that there are significant differences between morning and evening types in visual search but not in reasoning tasks (Natale et al., 2003).

Other studies report the influence of circadian type, time of day, and class difficulty on students' grades. It was showed that "optimal-time-of-day" had a significant effect on students' grade for difficult classes, and evening type students were most affected by standard class times (McElroy and Mosteller, 2006). Recently, Giampierto and Cavallera (2007) studied the influence of morning and evening on creative thinking in a sample of 120 subjects: 68 males and 52 females. They found that evening types are more capable of creative thinking than morning types but no differences between men and women were shown.

Megdal and Schernhammer (2007) investigated several correlations for poor sleepers in 131 high school students. Sleep deficit was reported in $80 \%$ of these students including $69 \%$ of girls and $58 \%$ of boys, respectively. Their results also showed that eveningness was strongly associated with sleeplessness.

Few studies addressed the influence of class attendance on performance. Romer (1993) investigated how absenteeism affects students' performance and learning. He found a statistically significant negative effect for absenteeism on students' performance (Romer, 1993). His study revealed that when students attend only a quarter of his class meetings, they earn an average grade of $C$ - and when they attend they attend all of the lectures, they earn a B+ (Romer, 1993). Other studies showed a direct correlation between grades and the number of absences (Durden and Ellis, 1995; Vodopich \& Moore, 2008; Zaru, 2010). The objectives of this study were to (1) compare students grades in morning versus afternoon science classes (2) investigate the influence of attendance on student's grades, and (3) compare male versus females grades. The science classes used were Principles of Biology (BIOL 150), General Botany (BOTN), and Microbiology and Immunology (BIOL 330) classes. Students' grades were monitored over a period of 3 years.

\section{Methods}

The influence of absences, class time, gender, class section, class difficulty and semester on grades of 621 students in three different classes: BIOL 150 (232 students), less difficult; BOTN 210 (207 students), intermediate; and BIOL 330 (182 students), difficult, were investigated over a period of 3 years (20062009) at Fayetteville State University (Table 1). The sample included 484 females (77.9\%) and 137 males (22.1\%) (Table 2). In assessments, students were asked the same question: "How do you choose the classes to take in a particular semester?" in all the sections of the three courses studied here. Students chose classes according to their schedule and not time preference (data no shown).

Means, ranges, and standard errors for the total number of days of absence, and grades were calculated and ANOVA was performed to check if factors such as absences, class time, gender, class difficulty and semester affect students' grades. Separation of the means was performed with the use of TukeyKramer test. Additionally, Pearson correlation coefficients were calculated to study relationships among the measured traits. Analyses were performed on JMP 8.02 (SAS Institute Inc., Cary, NC, USA).

\section{Results and Discussion}

The three undergraduate classes studied, BIOL 150, BOTN 210 , and BIOL 330 , including information about class times, semesters, and academic years used in this study are presented in Table 1.

Figures 1, 5 and 8 present the distribution of averages of grades for BIOL 150, BOTN 210, and BIOL 330 respectively. Figures 2 and 6 show the differences in means for grades in fall, spring, and summer semesters for BIOL 150 and BOTN 210, respectively. Figures 3 and 9 show average grades in different class times (morning and afternoon) for BIOL 150 and BIOL 330, respectively. Figures 4,7 , and 10 show bivariate fit of average grades by absences in BIOL 150, BOTN 210, and BIOL 330, respectively. Figure 11 shows average grades in the three classes.

\section{a. BIOL 150}

In BIOL 150 the mean grade of all students attended over the three studied years was 67.81 ( \pm 19.29 ) with a range from 8 to 100 (Fig. 1). ANOVA showed that a factor that significantly affected the average grade is semester (fall, spring, summer) at $\mathrm{P}>0.0001^{* * *}$. The average grades for summer semester were significantly higher than those for spring and fall at $\mathrm{P}>0.05$ (Fig. 2 ). Gender ( $P>0.7199$ ) and class section (example BIOL 150-1 vs. BIOL 150-4) ( $>>0.1320)$ did not seem to affect the average grade significantly. Class time seemed to have a significant effect $\left(P>0.0018^{* *}\right)$ on the performance of students. Students that attended afternoon classes got better grades (mean 71.27) than those whose attended morning ones (mean 63.34) (Fig. 3 ). Finally, the number of absences was a factor that affected grades significantly. The bivariate fit of average grade by absences in Fig. 4 showed the moderate but strongly significant negative correlation $\left(-0.69, \mathrm{P}>0.0001^{* * *}\right)$ between grades and number of absences, a result which is in agreement with other studies (Romer, 1993; Vodopich \& Moore, 2008; Zaru, 2010).

\section{b. BOTN 210}

In BOTN 210 the mean grade of all students over the three studied years was 77.33 with a standard deviation of 12.74 . The grades ranged from 7.5 to 100 while the $75 \%$ of students was over 85 (Fig. 5). Statistical analysis revealed that a factor that played an important role to students' performance is semester $\left(\mathrm{P}>0.005^{* *}\right)$. More specifically, students received better grades in summer and fall than in spring (Fig. 6). Other factors such as gender (male vs. female), class time (early morning vs. late morning), or class section (BOTN_1 vs. BOTN_2) did not af- 
Table 1. Undergraduate classes used in this study: Principles of Biology (BIOL 150), General Botany (BOTN 210), and Microbiology \& Immunology (BIOL 330). Times when these classes were conducted are shown below each class.

\begin{tabular}{|c|c|c|}
\hline Academic Year 2006-2007 & Academic Year 2007-2008 & Academic Year 2008-2009 \\
\hline Fall 2006 & Fall 2007 & Fall 2008 \\
\hline BIOL 150 (Section 1) & BIOL 150 (Section 1) & BIOL 150 - NA \\
\hline Section $1(11$ AM- 12 PM) & Section 1 (8-9 AM) & \\
\hline BOTN 210 (Sections 1\&2) & BOTN 210 (Sections $1 \& 2$ ) & BOTN 210 (Sections 1\&2) \\
\hline Section 1 (8-10 AM) & Section 1 (8-10 AM) & Section 1 (8-10 AM) \\
\hline Section 2 ( 10 AM- 12 PM) & Section 2 (10 AM- 12 PM) & Section 2 (10 AM- 12 PM) \\
\hline BIOL 330 (Sections 1\&2) & BIOL 330 (Sections 1\&2) & BIOL 330 (Sections 1\&2) \\
\hline Section $1(11$ AM - $12 P M)$ & Section 1 (9:30 AM - 10:30 AM) & Section 1 (9:30 AM - 10:30 AM) \\
\hline Section 2 (9 AM - $10 A M)$ & Section 2 (9:30 AM - 10:30 AM) & Section 2 (9:30 AM - 10:30 AM) \\
\hline Spring 2007 & Spring 2008 & Spring 2009 \\
\hline BIOL 150 (Section 1) & BIOL 150 (Section 1) & BIOL 150 (Section 1) \\
\hline Section $1(11$ AM - $12 P M)$ & Section 1 (8-9 AM) & Section 1 (9-10 AM) \\
\hline BOTN 210 (Sections 1\&2) & BOTN210 (Sections 1\&2) & BOTN 210 (Sections 1\&2) \\
\hline Section 1 (8-10 AM) & Section 1 (8-10 AM) & Section 1 (8-10 AM) \\
\hline Section 2 ( 10 AM- 10 PM) & Section 2 ( 10 AM- 12 PM) & Section 2 ( 10 AM- 12 PM) \\
\hline BIOL 330 (Sections 1\&2) & BIOL 330 (Sections 1\&2) & BIOL 330 (Sections 1\&2) \\
\hline Section 1 (9 AM - 10 AM) & Section 1 (9 AM - $10 A M)$ & Section 1 (9:30 AM - 10:30 AM) \\
\hline Section $2(10 A M-11 A M)$ & Section 2 (9 AM - $10 A M)$ & Section 2 (9:30 AM - 10:30 AM) \\
\hline Summer 2007 & Summer 2008 & Summer 2009 \\
\hline \multirow[t]{2}{*}{ BIOL 150 - NA } & BIOL 150 (Section 1) & BIOL $150($ Section 1$)$ \\
\hline & Section $1(10-11$ AM) & Section $1(11 A M-12 P M)$ \\
\hline BOTN $210($ Section 1$)$ & BOTN 210 (Section 1) & BOTN 210 (Section 1) \\
\hline Section 1 (8-10 AM) & Section 1 (8-10 AM) & Section 1 (8-10 AM) \\
\hline Section 2 ( 10 AM- 12 PM) & Section 2 (10 AM- 12 PM) & Section 2 (10 AM- 12 PM) \\
\hline BIOL 330 - NA & BIOL 330 - NA & BIOL 330 - NA \\
\hline
\end{tabular}

Table 2. The total numbers of student males and females in the three classes included in the study: Principles of Biology, General Botany, and Microbiology.

\begin{tabular}{llll}
\hline Course & Gender & No. of Students & Percentages \\
\hline Principles of Biology: & Females & 187 & $80.60 \%$ \\
& Males & 45 & $19.40 \%$ \\
& Total & 232 & $100 \%$ \\
General Botany: & Females & 162 & \\
& Males & 45 & $78.30 \%$ \\
& Total & 207 & $21.70 \%$ \\
Microbiology: & & & $100 \%$ \\
& Females & 135 & $74.20 \%$ \\
& Males & 47 & $25.80 \%$ \\
& Total & 182 & $100 \%$ \\
\hline
\end{tabular}




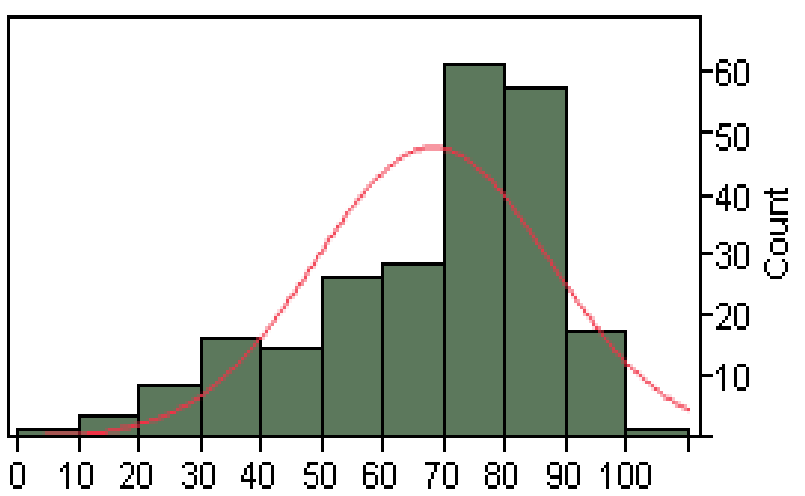

Grade

Fig. 1. Frequency distribution of average grades in $\mathrm{BIOL} 150$ from 2006-2008.

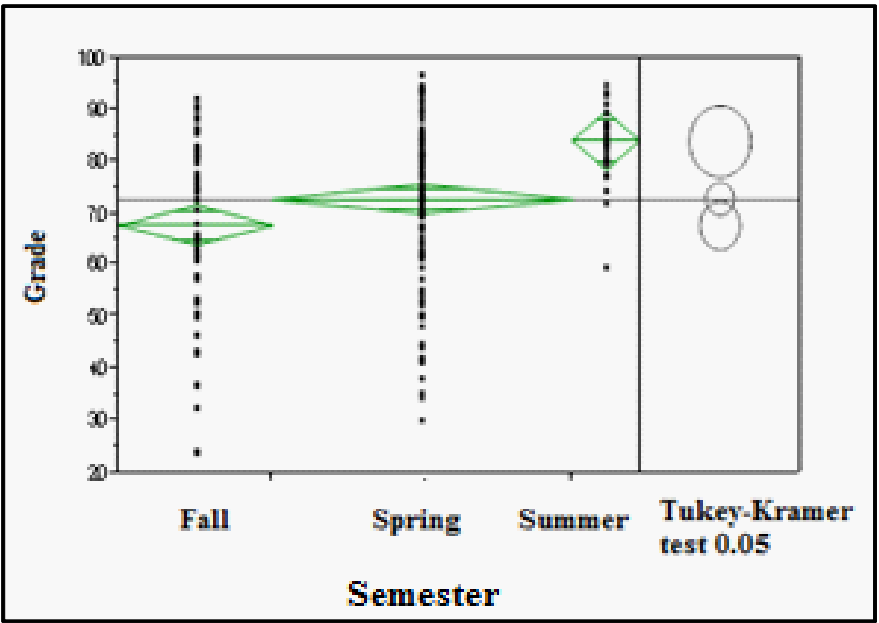

Fig. 2. Average grades in different semesters (fall, spring and summer) in BIOL 150 from 2006-2008.

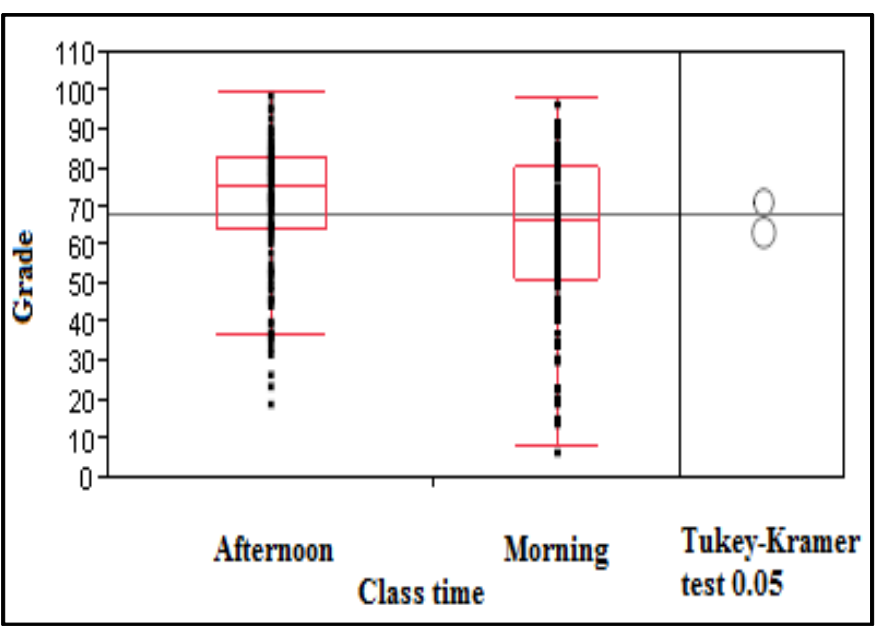

Fig. 3. Average grades in different class time (morning and afternoon) in BIOL 150 from 2006-2008.

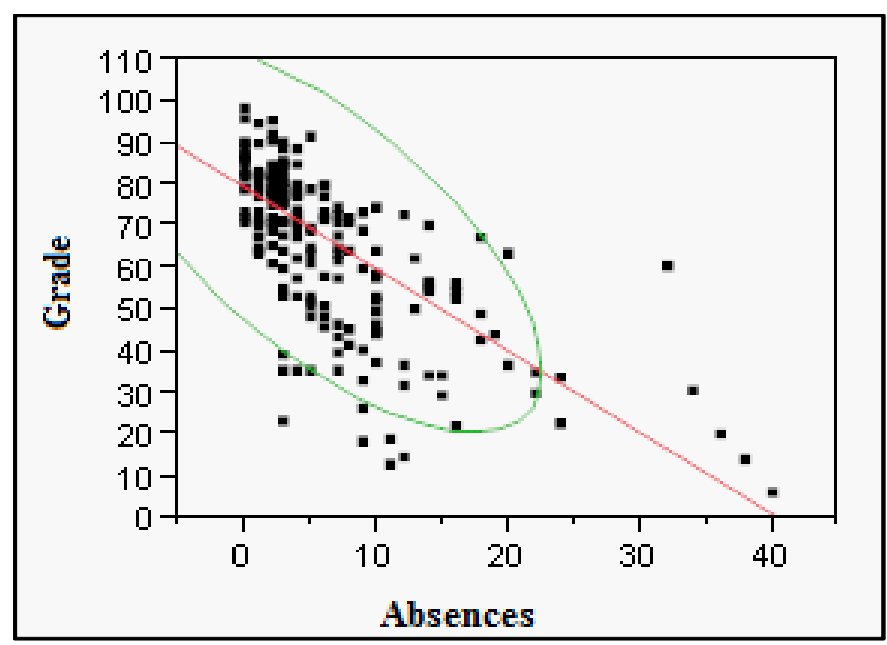

Fig. 4. Bivariate fit of average grades by absences in BIOL 150 from 2006-2008.

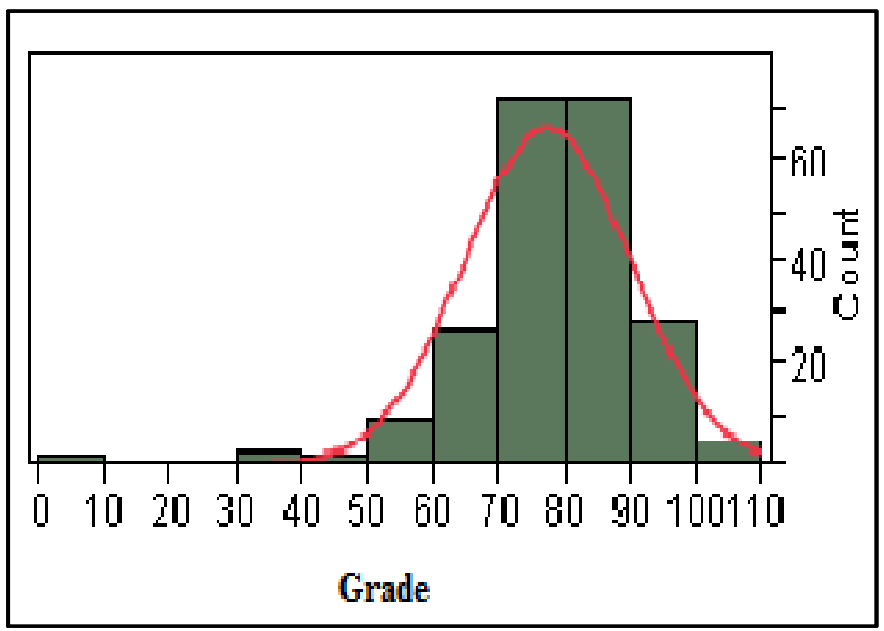

Fig. 5. Frequency distribution of average grades in BOTN 210 from 2006-2008.

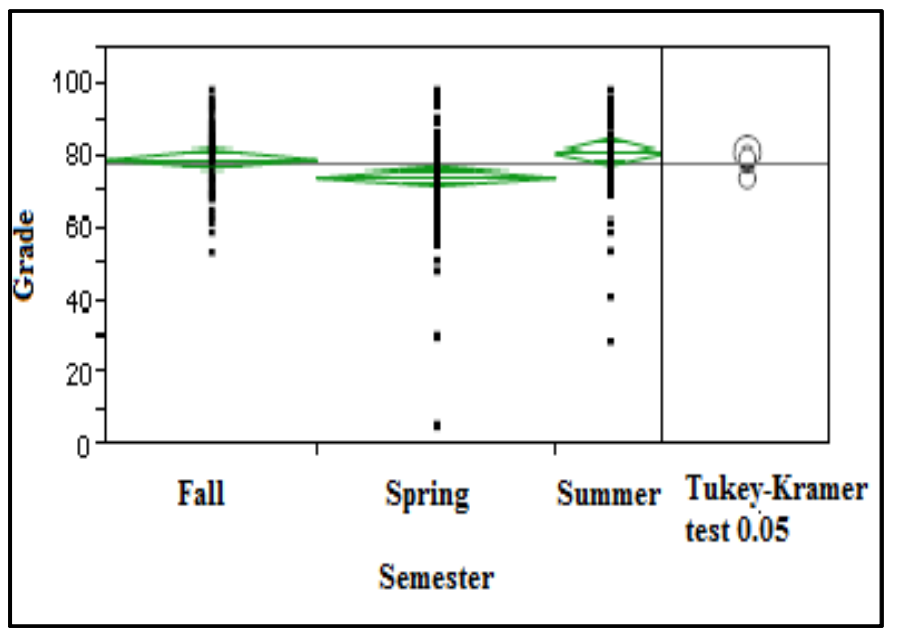

Fig. 6. Average grades in different semesters (fall, spring and summer) in BOTN 210 from 2006-2008. 


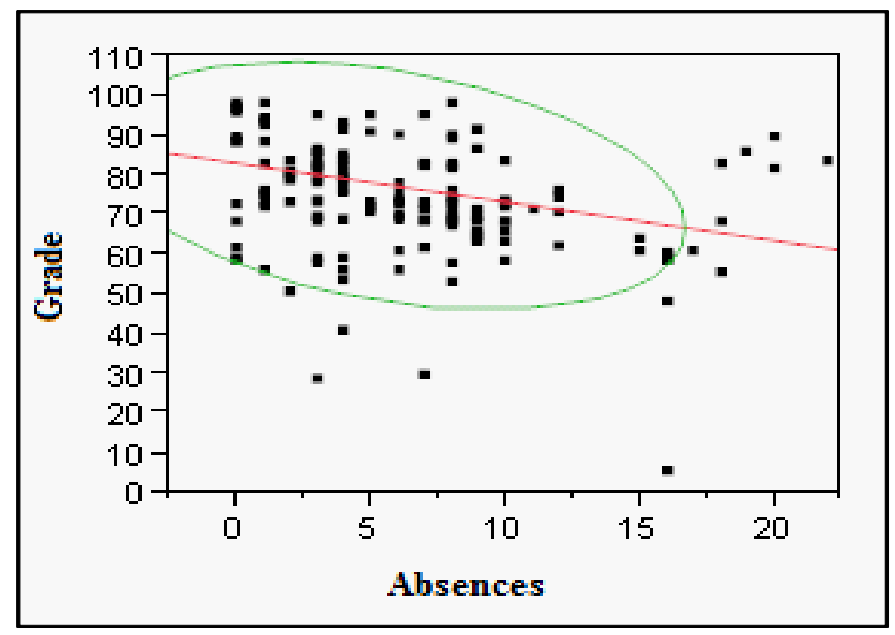

Fig. 7. Bivariate fit of average grades by absences in BOTN 210 from 2006-2008.

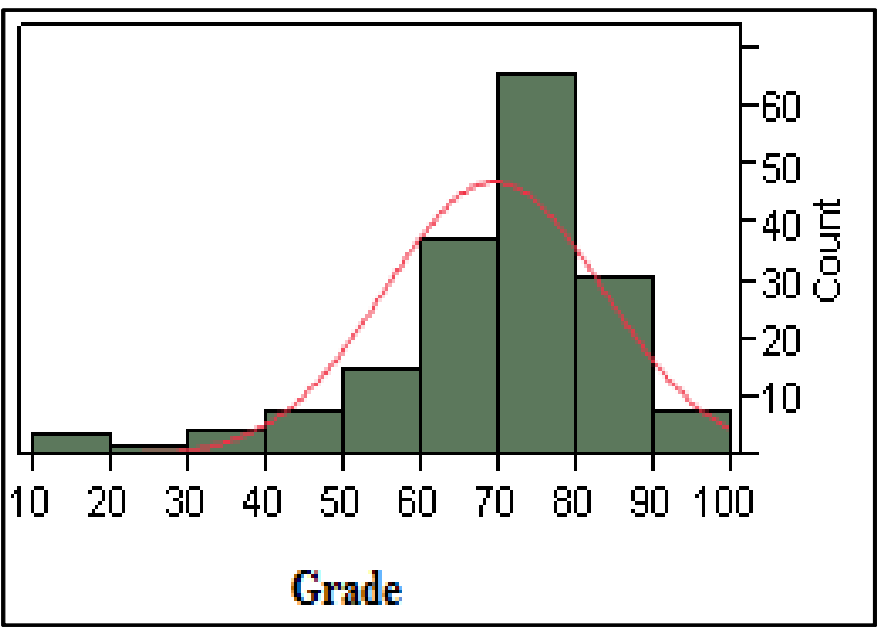

Fig. 8. Frequency distribution of average grades in BIOL 330 from 2006-2008.

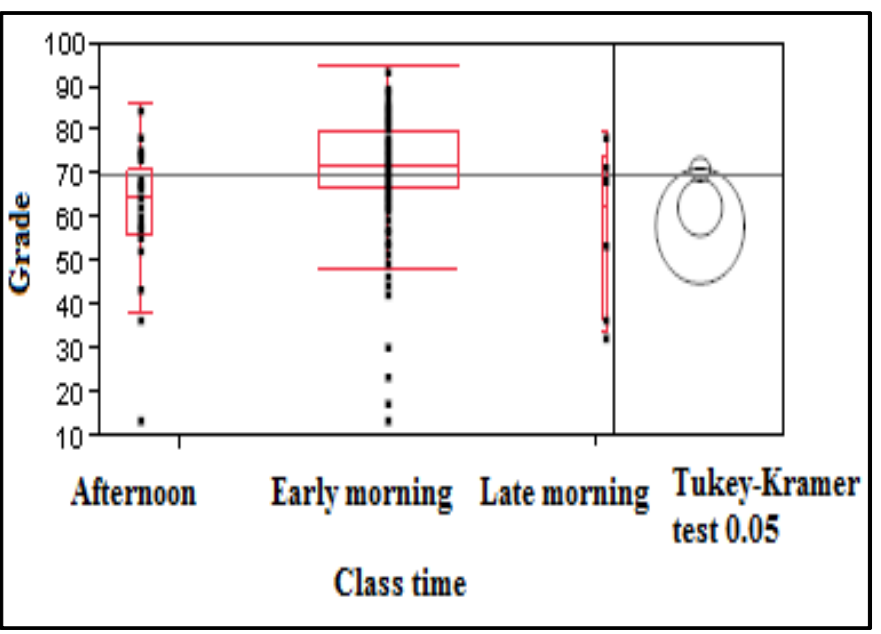

Fig. 9. Average grades in different class time (early or late morning and afternoon) in BIOL 330 from 2006-2008.

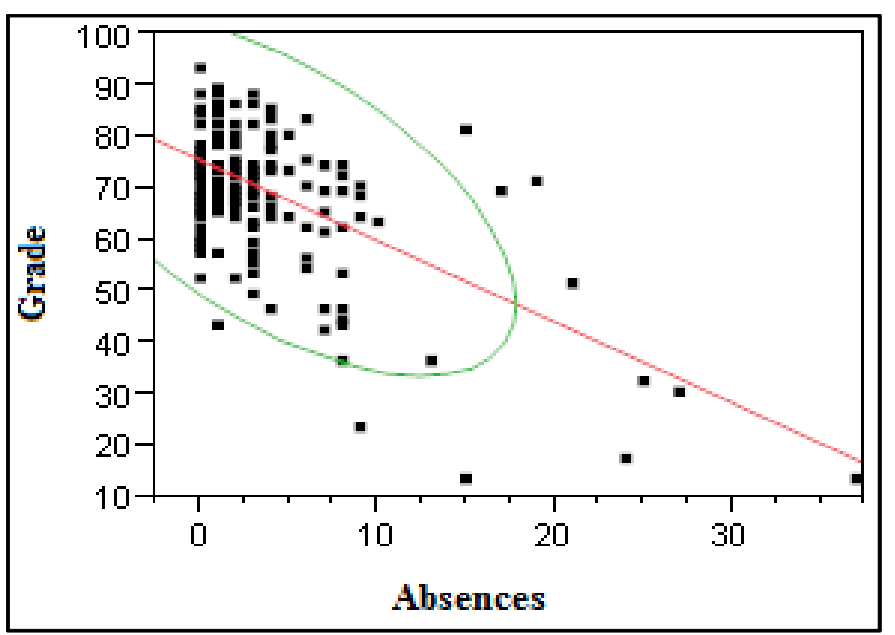

Fig. 10. Bivariate fit of average grades by absences in $\mathrm{BIOL} 330$ from 2006-2008.

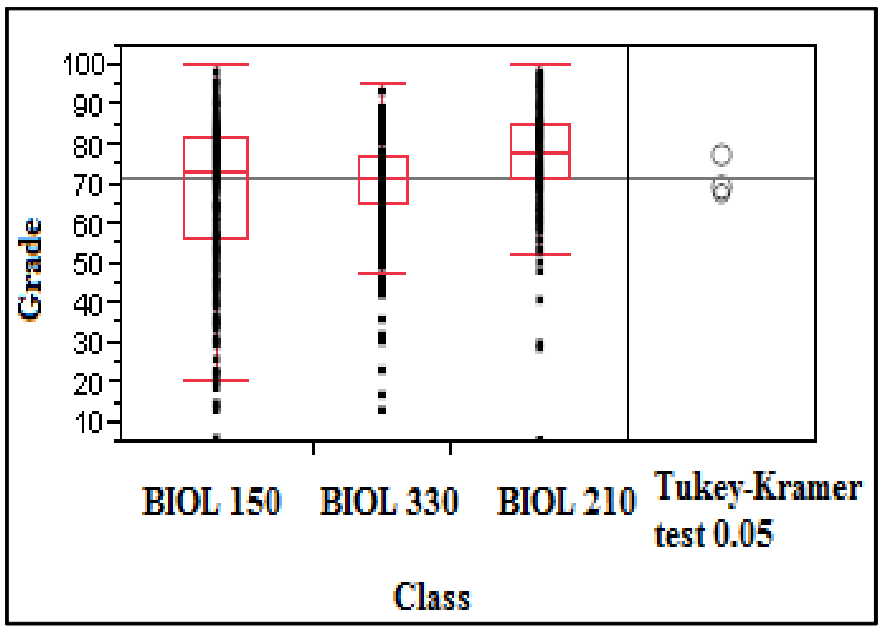

Fig. 11. Average grades in different classes (BIOL 150, BIOL 210 and BOTN 330) from 2006-2008.

fect grades significantly. Similar to the results from BIOL 150, the number of absences was again a factor that influenced grades. The bivariate fit of average grade by absences in Fig. 7 showed the strong negative correlation $\left(-0.34, \mathrm{P}>0.0001^{* * *}\right)$ between grades and number of absences which is once more in agreement with previously reported studies (Romer, 1993; Vodopich \& Moore, 2008; Zaru, 2010).

\section{c. BIOL 330}

Descriptive statistical analysis of grades in BIOL 330 exhibited a range from 15 as the minimum to 95 as the maximum with a mean value of 69.43 ( \pm 14.15$)$ (Fig. 8). From the studied factors, only class time appeared to play a role on grades. In early morning classes students received significantly better grades (mean 71.23) than those who attended late morning (mean 58.33) or afternoon classes (mean 62.58) (Fig. 9). These results are in agreement with previous reports (Kerkhof, 1985; 
Tankova et al., 1994; Natale and Lorenzetti, 1997; Natale and Adan, 1999; Natale et al., 2003; Giampietro and Cavallera, 2007). Among the students surveyed, $62.5 \%$ were afternoon like individuals and $37.5 \%$ were morning like individuals which is in agreement with the general trend that college students tend to have a $20-30 \%$ inclination towards eveningness (Akerstedt and Toesvall, 1981; Giampietro and Cavallera, 2007). In addition, once again, absences are a standard factor that influences grades in a negative way. Figure 10 shows the strong negative correlation $\left(-0.605, \mathrm{P}>0.0001^{* * *}\right)$ between the two variables.

\section{Conclusions}

Concerning class difficulty, the three courses under study are considered to require different level of effort. BIOL 150 is the least intensive class while $\mathrm{BIOL} 330$ the most demanding one. Analysis of students' performance over the years showed that in BOTN 210 the mean grade (77.33) was significantly higher than the means in BIOL 150 (67.82) and BIOL 330 (69.43).

Data revealed that class time played a significant role in the number of absences ( $P>0.0194 *$ ) indicating that the most "convenient" time for students is either 9:30-10:30 am or 4-6 $\mathrm{pm}$ when their attendance is more consistent. Also, it was also revealed that there is a significant difference in the number of absences between semesters ( $P>0.0268 *$,) and more specifically that student absences are more typical in fall than in spring semester. On the other hand, class section ( $P>0.3343)$ and gender ( $P>0.1362)$ are not factors that affect the number of absences. Grades and absences were not surprisingly (Vodopich \& Moore, 2008; Zaru, 2010) found to be negatively correlated (-0.605, $\left.\mathrm{P}>0.0001^{* * *}\right)$ and regression can be described as Average grade $=75.58601-1.57559 \times$ Absences .

In addition, analysis of grades revealed significant differences $\left(\mathrm{P}>.0001^{* * *}\right)$ beween the three classes studied ( $\mathrm{BIOL}$ 150, BIOI 330 and BOTN 210). Students tend to receive better grades in BOTN 210 than they do in BIOL 330 and BIOL 150 (Means 77.33, 69.42, and 67.82, respectively) (Fig. 11). This result does not coincide with the level of difficulty of these classes. Again, gender does not seem to affect grades significantly.

Significant differences ( $P>0.0126 *$ ) were observed in terms of absences between the three different classes (BIOL 150, BIOL 330 and BOTN 210). Students tend to be less typical in BIOL 150 than in BOTN 210 and BIOL 330. In general, students tend to have more absences when classes start earlier in the morning, 8,9 , or $10 \mathrm{AM}$.

In general, among the studied factors (absences, gender, class section, class difficulty and semester) for all three classes (BIOL 150, BOTN 210 and BIOL 330) absences seem to be the factor that affects the performance of students constantly in a negative way. Therefore, we suggest that American universities and colleges combat absenteeism whenever possible to boost students' performance. Students may perform better in morning or evening classes depending on the class. We believe that student performance is affected in early morning classes and suggest that Department Chairs avoid scheduling early morning science classes whenever possible.

\section{References}

Akerstedt T and L Toesvall (1981) Shiftwork: Shift dependent wellbeing and individual differences. Ergonomics 24: 265-273.

Gates Al (1916) Diurnal variations in memory and association. University of California Publications in Psychology 1: 323-344.

Durden GC and LV Ellis (1995) The Effects of Attendance on Student Learning in Principles of Economics. The American Economic Review 85 (2): 343-346.

Giampietro M and GM Cavallera (2007) Morning and evening types and creative thinking. Personality and Individual Differences 42: 453-463.

Kerkhof GA (1985) Inter-individual differences in the human circadian system: a review. Biol Psycol 20: 83-112.

Laird DA (1925) Relative performance of college students as conditioned by time of day on day of week Journal of Experimental Psychology 3: 50-63.

McElroy T and L Mosteller (2006) The influence of circadian type, time of the day, and class difficulty on student's grade. Electronic Journal of Research in Educational Psychology 104 (3): 611-622.

Megdal SP and ES Schernhammer (2007) Correlates for poor sleepers in a Los Angeles high school. Sleep Medicine 9 (1): 60-63.

Melendez S (2004) From humble beginnings come great achievement. In Reflections on 20 years of minorities in higher education and the ACE annual status report. American Council on Education pp. 5-9.

Natale $V$ and A Adan (1999) Season of birth modulates morningnesseveningness preference in humans. Neuroscience Letters 274: 139-141.

Natale $V$ and R Lorenzetti (1997) Influences of morningness-eveningness and time of day on narrative comprehension. Personality and Individual Differences 23 (4): 685-690.

Natale V, A Alzani, and P Cicogna (2003) Cognitive efficiency and circadian typologies: a diurnal study. Personality and Individual Differences 35: 1089-1 105 .

Noguera FA (2003) The Trouble with Black Boys: The Role and Influence of Environmental and Cultural Factors on the Academic Performance of African American Males. Urban Education 38 (4): 431-459.

Romer D (1993) Do students go to class? Should they? Journal of Economic Perspectives 7 (3): 167-174.

Tankova I, A Adan, and G Buela-Casal (1994) Circadian typology and individual differences. A review. Person Individ Diff 16 (5): 671-684.

Vodopich DS and R Moore (2008) Welcome to the Biology Laboratory. In Biology Lab Manual. 8th eds. McGraw-Hill Companies, Inc. USA.

Zaru D (2010) Graduation rates reveal disproportionate patterns based on gender and race. The Guilfordian Newspaper 96 (20): 1 and 96 (20): 4-5. 